\title{
Property of poly(hydroxybutyrate) complexed polymer with soy protein isolate using glycerol as a medium
}

\author{
Xiaolu Ma,${ }^{12}$ Guoxiang Cheng ${ }^{1 *}$ \\ ${ }^{1 *}$ School of Materials Science and Engineering, Tianjin University, Tianjin 300072 , \\ China; tel: 8622 27404432; email: gxcheng@tju.edu.cn \\ ${ }^{2}$ Department of Mechanical Engineering, Henan industry University, Zhengzhou \\ 450052, China.
}

(Received: 09 June, 2008; published: 07 August, 2010)

\begin{abstract}
A kind of poly(hydroxybutyrate) complexed polymer with soy protein isolate $(\mathrm{PcSg})$ was prepared using glycerol as a medium. Effect of content of SPI on thermal, mechanical properties and water absorption of the PcSg polymer was investigated. The results indicated that SPI not only is miscible with PHB, but also may improve tenacity. The $\mathrm{PcSg}$ polymer displayed single glass transition ranges on their differential scanning calorimetry (DSC) curves. The fracture stress and Yang's modulus of the PcSg increased with PHB concentration, but fracture elongation declined. Water absorption of the PcSg was estimated by water absorption rate of the polymers. By the ratio of hydrophobic PHB and hydrophilic SPI, water absorption of the PcSg was efficaciously modified. It was proposed that the effect on the PcSg mainly was because of intermolecular interactions between PHB and SPI.

Keywords: complexed polymer; property; poly(hydroxybutyrate); soy protein isolate; glycerol; water absorption; macromolecular imprinting matrix.
\end{abstract}

\section{Introduction}

Soy protein isolate (SPI) is derived from soybean or byproduct of soy oil production, mainly composed of conglycinin (7s) and glycinin (11s) oligomers [1-6]. The 7s is a trimeric glycoprotein composed of six different combinations of three subunits, $\alpha, \alpha$ ' and $\beta$, associated via hydrophobic interactions. The 11s consists of two apposed hexagonal rings each containing three hydrophobically associated pairs of disulfidelinked acidic and basic subunits. Many reactive groups, such as amino, carboxyl and hydroxyl, are contained on the side chains molecules of both globulins. The macromolecular structures and properties of SPI are sensitive to physical and chemical actions [7-20]. When SPI is heated, the subunits of the two globulins may be dissociated and reassociated, altering the original three-dimension structures, exposing hydrophilic groups such as $\mathrm{C}=\mathrm{O}$ and $\mathrm{NH}$ of polypeptide chains, side chain amine groups and hydrophobic groups which originally engaged in intramolecular interactions by hydrophobic forces such as hydrogen bands and electrostatic action. Under action of heat, chemical reagents or protein enzymes, SPI may be modified according to some needs. With natural polyol-based biopolymers such as cellulose, starch and chitin, SPI may be higher potential on substituting for petrochemicalplastic products and processes as well as solving environment pollution from them $[10-17,21]$. Except application investigation on other aspects, SPI-based polymer was considered as a potential nonfood application [10-11, 21-24]. Recently, some novel hydrogel polymeric material derived from natural source such as alginate have 
been used as the matrix for macromolecular imprinting. It is forecastted that the soybean protein isolate (SPI) have a good prospect as an imprinting matrix, but its properties in aqueous medium needs improvement [25-28].

Poly(3-hydroxybutyrate) (PHB) is one of the most attractive natural polymers derived from renewable bioresource. Previous studies have demonstrated that PHB has always been found in association with specific proteins in biological cells [29-30]. In the past years, PHB has been modified by many methods such as blending and chemical or biosynthesis copolymerizing with other polymers [31-41]. PHB and its modified polymers such as multiblock copolymer consisting of poly(3hydroxybutyrate) and poly(ethylene glycol) have been studied as molecular imprinting matrix [42].

In the present paper, poly(hydroxybutyrate) complexed polymer with soy protein isolate using glycerol as a medium ( $\mathrm{PcSg}$ ) was prepared to modify the mechanical property and water absorption for further molecular imprinting research.

\section{Results and discussion}

Thermal property of PCSg with content of SPI

The DSC curves of PHB, SPIg and PcSg polymers, from secondary heating, were demonstrated in Figure 1. It was observed that the specimens showed only single glass transition temperature on each DSC curve, and $T_{g}$ of the $\mathrm{PcSg}$ polymers decreased with increase of PHB content (see Figure 2).

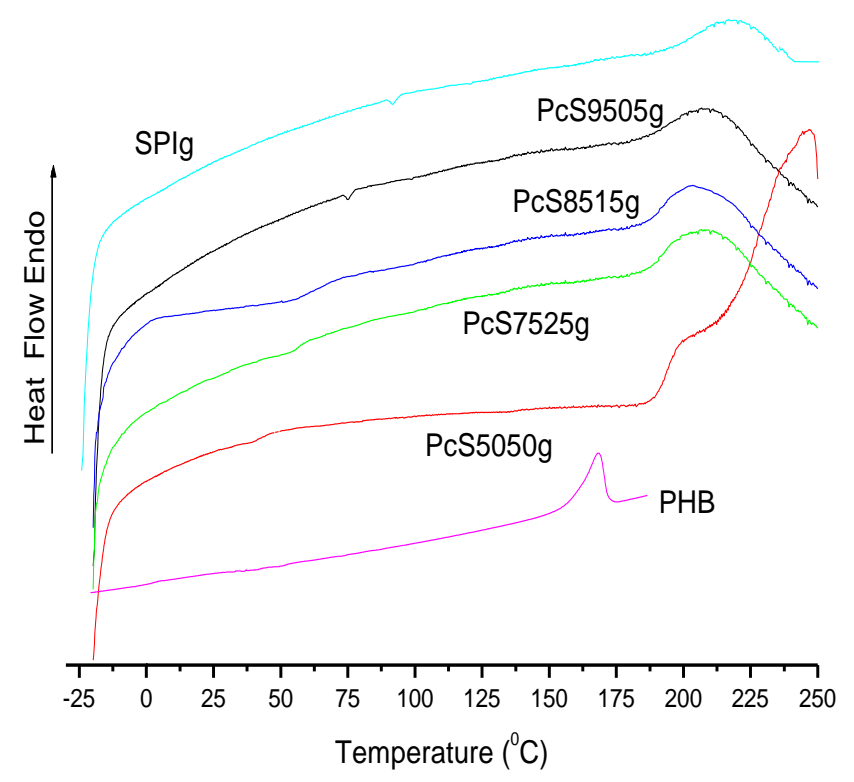

Fig. 1. The DSC curves of SPIg, PHB and PcSg polymers.

This implies that SPI is miscible with PHB. It was proposed that the major reason is intensive intermolecular interactions of SPI with PHB after denaturing of the protein. When being blended and heated, SPI denatured so that self-assembly bands of conglycinin and glycinin oligomers were cleaved [7-9, 14]. This prompted 
compounding reactions of the protein macromolecules with PHB ones. The intermolecular interactions may be ascribed to hydrogen bonds between protein macromolecules of SPI and those of PHB (see Scheme 1) [10, 18-20].

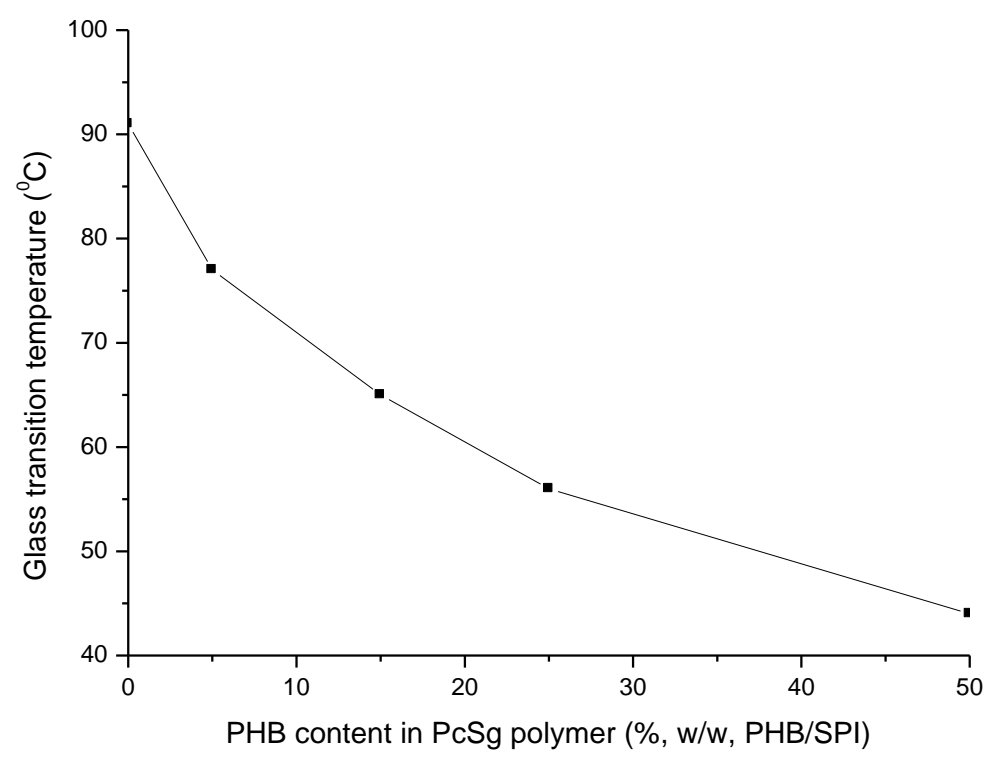

Fig. 2. Effect of PHB content in PcSg polymer on glass transition temperature.

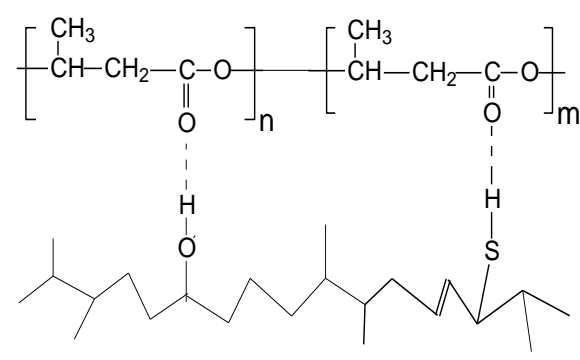

(a)

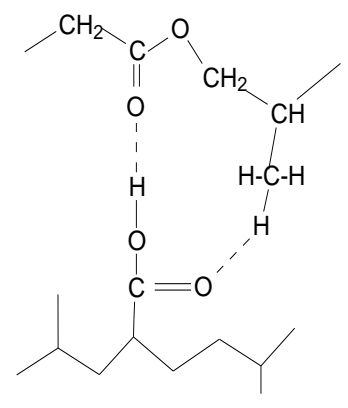

(c)

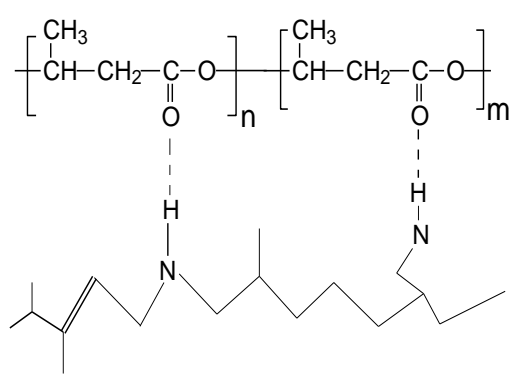

(b)

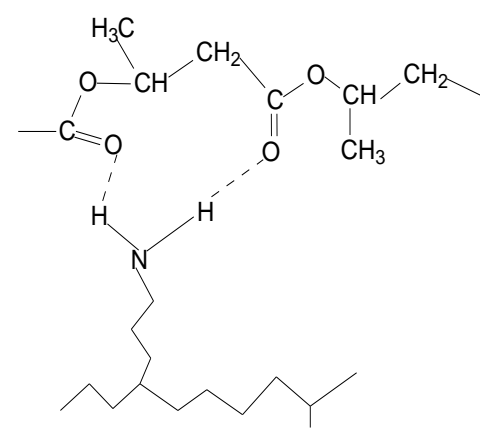

(d)

Scheme 1. The intermolecular interactions of SPI and PHB via association by intermolecular hydrogen bonding. 
The intermolecular interactions made the soy protein macromolecules reassociated with ones of PHB. Consequently, SPI and PHB formed a compatible complexed polymer. A further analysis for the DSC result may assist the suggestion. By the Kwei equation [43]:

$T_{g}=\left(W_{1} T_{g 1}+K W_{2} T_{g 2}\right) /\left(W_{1}+K W_{2}\right)+q W_{1} W_{2}$

An interaction parameter q between SPI with PHB may be obtained:

$q=-\left(\left(W_{1} T_{g 1}+K W_{2} T_{g 2}\right) /\left(W_{1}+K W_{2}\right)-T_{g}\right) / W_{1} W_{2}$

where $T_{g}$ is the glass transition temperature of the blends, $T_{g 1}$ and $T_{g 2}$ represent respectively those of pure components, $\mathrm{W}$ is the weight fraction of each component, whereas q may be considered as a measure of strength for specific interactions between the two kind of macromolecules, that is, the secondary term of the right side in the equation accounts for those interactions in the blends. When $q=0$, it is implied that there is a state of equilibrium between the interactions from the different molecular chains and those from the same ones. When $q>0$, it could be suggested that the interactions between the different molecular chains are stronger, otherwise the conclusion is reverse. $\mathrm{K}$ is the ratio of the two special heat increments before and after glass transition. When a special heat increments before glass transition is near to those after the transition, the $\mathrm{K}$ may be thought as 1 , then

$q=-\left(\left(W_{1} T_{g 1}+W_{2} T_{g 2}\right)-T_{g}\right) / W_{1} W_{2}$

The q values estimated by equation (3) closed gradually toward zero with increase of PHB component for the PcSg polymers although they were negative (see Figure 3). This revealed, for the PHB/SPI system, that addition of PHB weakened the intramolecular interactions of soy protein molecules and at the same time swelled the intermolecular interactions between the proteins and PHB. It implied that conglycinin and glycinin oligomers of soy protein were disassociated in heat-compress molding process and many of the protein macromolecules could not be assembled together with each other, but the proteins interacted with PHB chains.

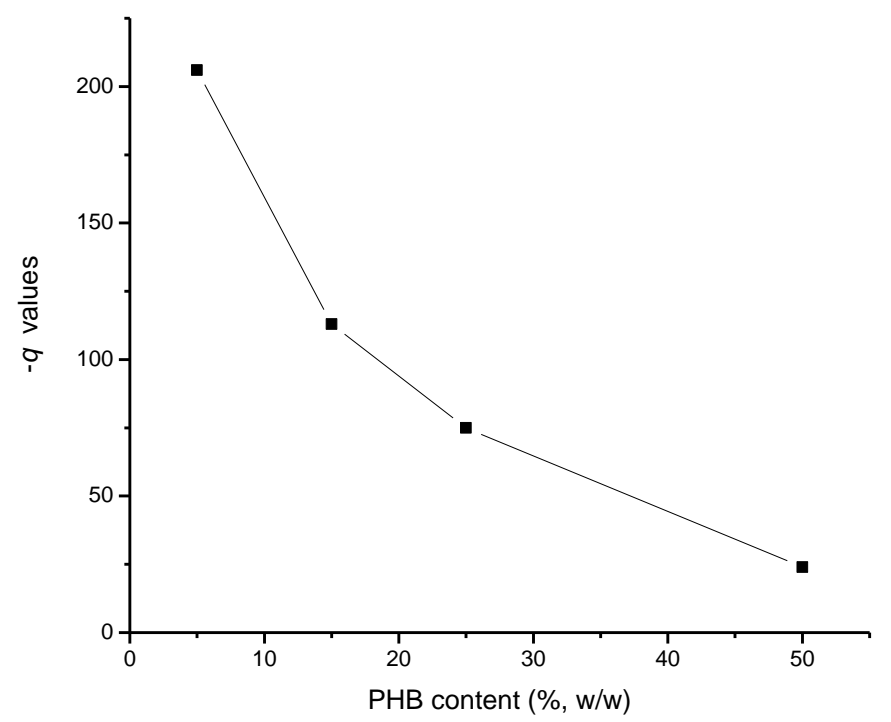

Fig. 3. Effect of PHB content in PcSg polymer on the interaction parameter. 


\section{Effect of PHB on mechanical properties}

The stress-strain curves of PcSg polymer specimens as well as fracture stress, Yang's modulus and fracture elongation are exhibited in Figure 4 and Figure 5.

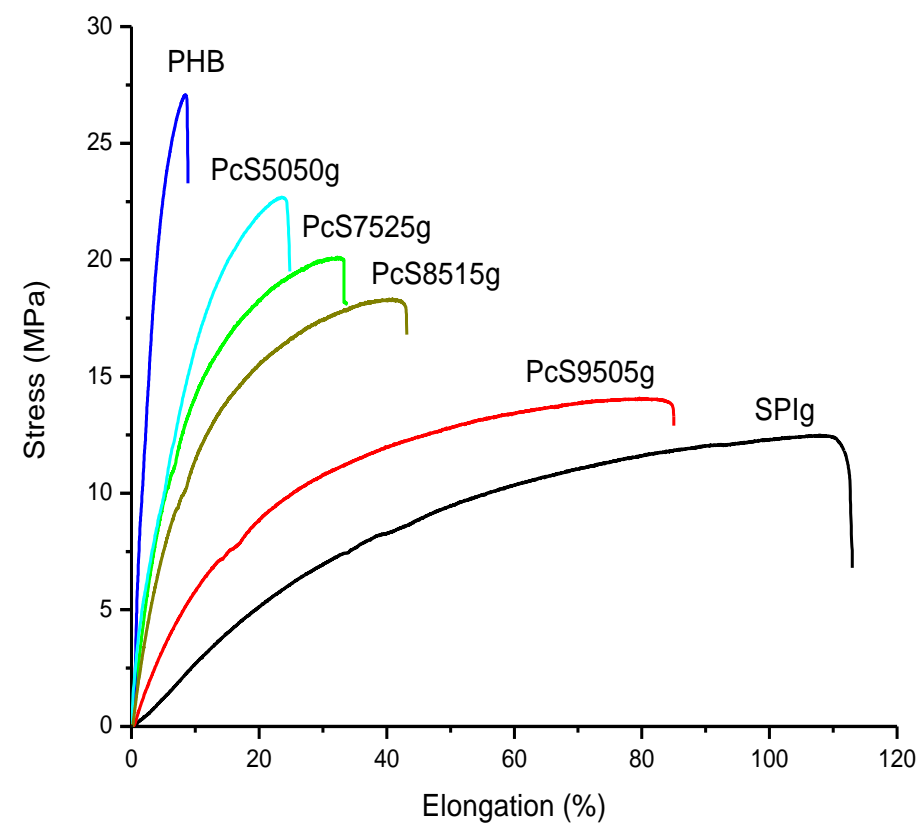

Fig. 4. Stress - strain curves of SPIg, PHB and PcSg polymers.

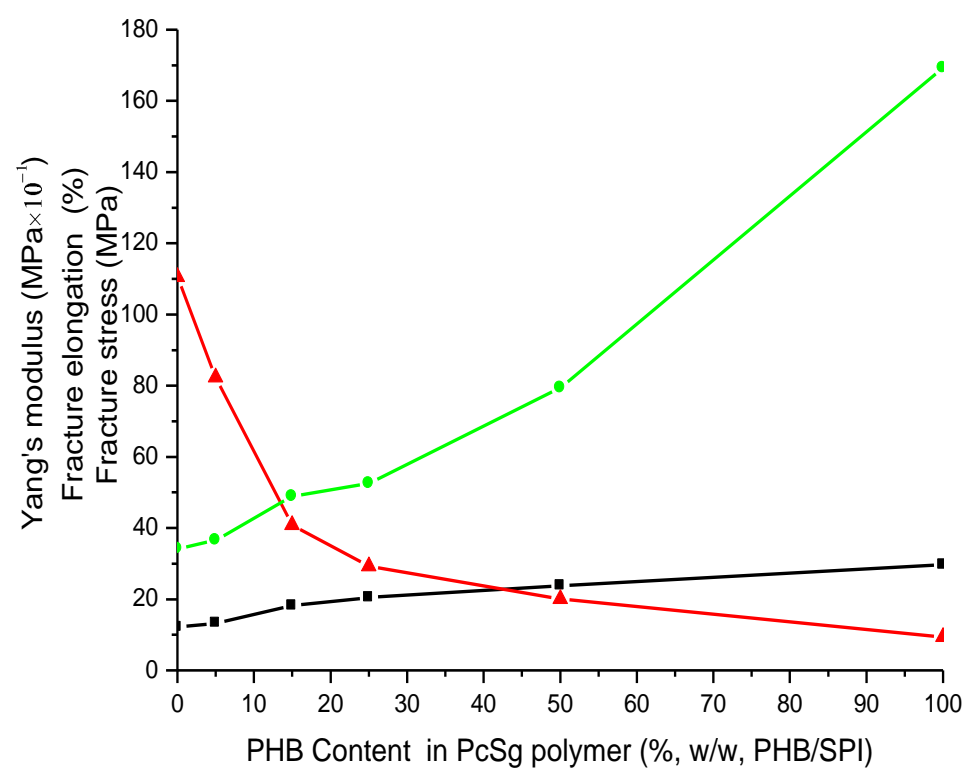

Fig. 5. The relation of fracture stress $(\bullet)$, Yang's modulus $(\bullet)$ and fracture elongation $(\mathbf{\Delta})$ of the PcSg polymers with PHB content. 
With addition of PHB, fracture stress and Yang's modulus of the PcSg polymers were improved in comparison with SPIg, increasing respectively from 12.1 to $22.4 \mathrm{MPa}$ and from 347 to $794 \mathrm{MPa}$ at room temperature and air conditions. But relative fracture elongations decreased from $110 \%$ to $20 \%$ with PHB concentration. It can be explained that the intermolecular interactions provided intensive cohesion energy between SPI, PHB and glycerol. Conversely, the crystal growth of PHB domain influenced the brittleness and fracture elongation.

\section{Effect of water absorption}

Effect of PHB on water absorption of the PcSg polymer was estimated by their water absorption rates. The relation of water absorption rate with time is exhibited in Figure 6. It may be seen that water absorption rates of the PcSg polymer were greatly reduced with increase of PHB. It is considered that hydrophobic PHB dispersed in interface of SPI globulin, indicated infiltration of water into SPI. In other words, SPI can modify hydrophilicity of the PcSg polymer for further imprinting matrix [44-45].

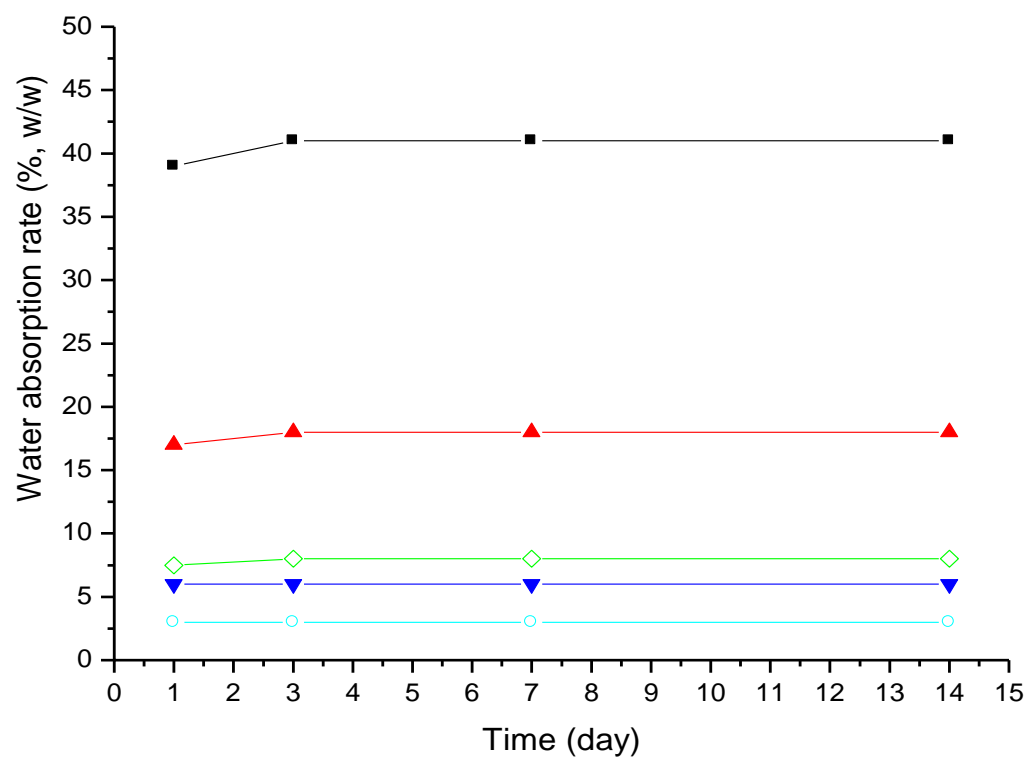

Fig. 6. Effect of PHB on water absorption rate of PcSg polymers. SPIg (匹), PcS9505g

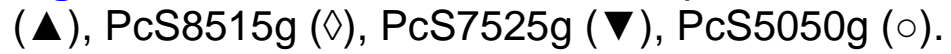

\section{Conclusions}

In this work, poly(hydroxybutyrate) complexed polymer with soy protein isolate (PcSg) was prepared using glycerol as a medium by mechanically blending via intermolecular association. Effect of content of SPI on thermal, mechanical properties and water absorption of the PcSg polymer was investigated. The results indicated that the fracture stress and Yang's modulus of the PcSg increased with PHB concentration, but fracture elongation declined. By the ratio of hydrophobic PHB and hydrophilic SPI, water absorption of the PcSg was efficaciously modified. It would be appropriate to use PcSg as molecular imprinting matrix in later work. 


\section{Experimental part}

\section{Materials}

The SPI (molecular weight about $320 \mathrm{KDa}$ ) was purchased from Haerbin Advanced Science and Technology Co. Ltd. (Haerbin, China). It contained $95 \%$ (dry basis) protein, less than $1 \%$ polysaccharide, $4 \%$ ash and $6.5 \%$ moisture $(\mathrm{w} / \mathrm{w})$. The protein was dried at $50{ }^{\circ} \mathrm{C}$ and atmosphere pressure for $24 \mathrm{~h}$. The moisture content of the dried SPI was $2.3 \%(\mathrm{w} / \mathrm{w})$. The PHB used in this work were provided by Tianjin TianLu Co. Ltd. (Tianjin, China), $M_{w}=430 K, M_{n}=290 K, M_{w} / M_{n}=1.48$ (by GPC), industrial grade (>93\%, w/w), which was purified by our previous study [11]. Other chemicals were all analytical grade.

\section{Preparation of PcSg complexed polymer}

The above SPI dried was blended with PHB and glycerol at $11000 \mathrm{rpm}$ in a highspeed blender (Guangdong Yihe Co., China) for $6 \mathrm{~min}$, followed by repeated mixing at $125{ }^{\circ} \mathrm{C}$ in an open mill with molars. The ratio of SPI with PHB and the codes of the $\mathrm{PcSg}$ samples are listed in Table 1 . The concentration of glycerol was $25 \%(\mathrm{w} / \mathrm{w})$ of sum of SPI and PHB in each sample. Single SPI with 25\% glycerol was signed SPIg. Glycerol was not added in pure PHB sample. Subsequently, SPIg and pure PHB as well as the blends were respectively molded into plastic sheets in a compressmolding machine (Tianjin Xinke Co., China) by two steps: first pre-pressing at $130^{\circ} \mathrm{C}$ and a pressure of $10 \mathrm{MPa}$ for $20 \mathrm{~min}$; after taking off the pressure, repressing at 160$170{ }^{\circ} \mathrm{C}$ and a pressure range of $20-30 \mathrm{MPa}$ for $5-10 \mathrm{~min}$. The plastics sheets were kept at room temperature and air conditions (relative humidity about $60 \%$ ) for two weeks before test.

Tab. 1. Preparing method and sample code of PcS complexed polymers.

\begin{tabular}{ccc}
\hline Sample code & $\begin{array}{c}\mathrm{PHB} / \mathrm{SPI} / \mathrm{glycerol}, \\
\text { wt/wt }\end{array}$ & Preparing method \\
\hline PHB & $100 / 0 / 0$ & pure \\
PcS9505g & $95 / 5 / 25$ & mechanically blending \\
PcS8515g & $85 / 15 / 25$ & mechanically blending \\
PcS7525g & $75 / 25 / 25$ & mechanically blending \\
PcS5050g & $50 / 50 / 25$ & mechanically blending \\
SPIg & $0 / 100 / 25$ & mechanically blending \\
\hline
\end{tabular}

\section{Differential scanning calorimetry (DSC)}

The differential scanning calorimetry curve was performed using a Perkin-Elmer DSC 7 (Perkin-Elmer Co., USA). All samples were first heated from $20^{\circ} \mathrm{C}$ to $185^{\circ} \mathrm{C}$ at a rate of $15{ }^{\circ} \mathrm{C} / \mathrm{min}$ followed by maintaining the temperature $5 \mathrm{~min}$, subsequently cooled to $-20{ }^{\circ} \mathrm{C}$ at $-150^{\circ} \mathrm{C} / \mathrm{min}$, then again heated to $230^{\circ} \mathrm{C}$ at $15^{\circ} \mathrm{C} / \mathrm{min}$.

\section{Testing of Mechanical properties}

The stress - strain curve were measured by a universal testing machine (CMT-6503, Shenzhen SANS Test Machine Co. Ltd., China) at a tensile speed $10 \mathrm{~mm} / \mathrm{min}$ at room temperature and $57 \%$ relative atmospheric humidity. 
Water absorption tests

Water absorption tests of the SPI/PHB plastics specimens were performed with the tensile testing specimens. Three samples for each treatment were used in the test. After being weighed, the specimens were submerged in deionized water at $24{ }^{\circ} \mathrm{C}$. The specimens were respectively taken out after 3, 7, 14 and 21 day, and dried with towels followed by immediate weighing. The water absorption rate was calculated by the equation (4):

$\pi=\frac{W_{i}-W_{0}}{W_{0}} \times 100 \%$

where $\pi$ is percent water absorption rate, and $W_{i}$ described each specimen weight at each measure, $\mathrm{W}_{0}$ was the initial weight of each specimen.

\section{References}

[1] Thanh, V.H.; Shibasaki, K.J. Agric. Food. Chem. 1978, 26, 695.

[2] Kinsella, J.E. J. Am. Oil Chem. Soc. 1979, 56, 242.

[3] Badley, R.A.; Atkinson, D.D.; Hauser, H.; Oldani, D.; Green, J.P.; Stubbs, J.M. Biochim. Biophys. Acta 1975, 412,214.

[4] Hermasson, A.M. J. Agric. Food. Chem. 1985, 36, 822.

[5] Plietz, P.; Zirwer, D.; Schelsier, B.; Gast, K.; Damashung, G. Biochim. Biophys. Acta 1984, 784, 140.

[6] Plietz, P.; Damaschun, G. Biophys. 1986,116, 153.

[7] Wu, Y.V.; Inglet, G.E. J. Food Sci. 1974, 39, 218.

[8] Franzen, K.L.; Kinsella, J.E. J. Agric. Food Chem. 1976, 24, 788.

[9] Wang, C.H.; Damodaran, S. J. Agric. Food Chem. 1991, 39, 433.

[10] Paetau, I.; Chen, C.; Jane, J. Ind. Eng. Chem. Res. 1994, 33, 1821.

[11] Sue, H.J.; Wang, S.; Jane, J. Polymer 1996, 38, 5035.

[12] Vaza, C.M.; Doeverenb, P.F.; Reisa, R.L.; Cunha, A.M. Polymer 2003, 44, 5983.

[13] Heteriarachy, N.S.; Kalapathy, U.; Meyer, D.J. J. AM. Oil Chem. Soc. 1995, 72, 1461.

[14] Kalapathy, U.; Hettiarachchy, N.S.; Myers, D.J.; Rhee, K.C. J. Am. Oil Chem. Soc. 1996, 73, 1063.

[15] Brandenburg, A.H.; Weller, C.L.; Testin, R.F. J. Food Sci. 1993, 58, 1086.

[16] Hwang, D.C.; Damodaran, S. J. Agric. Food Chem. 1996, 44, 751.

[17] Li, G.Q. China Patent 2001, CN1429936A.

[18] Haris, P.; Severcan, F. J. Mol. Cataly-Enzymatic B 1999, 7, 207.

[19] Souillac, P.O.; Middaugh, C.R.; Rytting, J.H. Int. J. Pharm. 2002, 235, 207.

[20] Subirade, M.; Kelly, I.; Gueguen, J.; Pezolet, M. Int. J. Bio. Macromol. 1998, 23, 241.

[21] Myers, D.J. Cereal. Foods World 1993, 38, 355.

[22] Zhang, J.; Mungra, P. Jane, J. Polymer 2001, 42, 2569.

[23] Otaigbe, J.; Adams D. J. Environ. Polym. Degrad. 1997, 5, 199.

[24] Wang S.; Sue, H.J.; Jane, J. J. Macromol. Sci-Chem A 1996, 33, 557.

[25] Zhang, F.J.; Cheng, G.X.; Ying, X.G. Reac.Func.Polym. 2006, 66, 712.

[26] Zhao, K.Y.; Huang, J.J.; Ying, X.G.; Cheng, G.X. J.Appl. Polym. Sci. 2008, 109, 2687.

[27] Zhai, X.C.; Ma, X.L.; Cheng, G.X. Science paper Online, http://www.paper. edu.cn 2008, no.271. 
[28] Zhai, X.C.; Ma, X.L.; Cheng, G.X. Sciencepaper Online, http://www.paper.edu.cn 2008 , no.283

[29] Huang, R.; Reusch, R.N. J. Biol. Chem. 1996, 271, 22196.

[30] Seebach, D.; Fritz, M.G. Int. J. Biol. Macromol. 1999, 25, 217.

[31] Yuan, Y.; Ruckenstein, E. Polymer 1998, 39,1893.

[32] Rafael, S.; Gizilene, M.C.; Edvani C. M.; Gentil J. V.; Adley F.R. e-Polymers, http://www.e-polymers.org, 2007, no.134

[33] Ei-Hadi, A.; Schnabel, R.; Straube, E.; Muller, M.; Riemschneider, M. Macromol. Mater. Eng., 2002, 287, 363.

[34] Cheng, G.X.; Ma, S.H.; Ma, M.; Zhang, L.G. Mater. Sci.Tech. 2001, 9, 148.

[35] Wang, T.Z.; Cheng, G.X.; Ma, S.H.; Cai, Z.J.; Zhang, L.G. J. Appl. Polym. Sci. 2003, 89, 2116.

[36] Cheng, G.X.; Cai, Z.J.; Wang, L. J. Mater. Sci. Mater. Med. 2003, 14, 1073.

[37] Cai, Z.J.; Cheng, G.X.; Geng, M.M.; Tang, Z.Y. J. Polym. Res. 2004, 11, 99.

[38] Cheng, G.X.; Wang, T.Z.; Zhao, Q.; Ma, X.L.; Zhang, L.G. J. Appl. Polym. Sci. 2006, 100, 1471.

[39] Zhao, Q.; Cheng, G.X. J Mater Sci, 2004, 39, 3829.

[40] Zhao, Q.; Cheng, G.X., Li, H.M.; Ma, X.L.; Zhang, L.G. Polymer 2005, 46,10561.

[41] John, L.; Foster, R. Appl. Microbiol. Biotechnol. 2007, 75, 1241.

[42] Cheng, G.X.; Ma X.L.; Zhao Q.; Li H.M.; Tian F. Reac.Func.Polym. 2008, submitted

[43] Kwei, T.K. J. Polym. Sci. Lett. 1984, 22, 307.

[44] Pang,X.S.; Cheng, G.X. in Robert K. Bregg, Polym. Res. Develop. Nova Sci.

Pub. 2006, 91

[45] Zhao, K.Y.; Cheng, G.X.; Huang, J.J.; Ying, X.G.; Reac.Func.Polym. 2008, 68, 732. 